\title{
Clinical Implications of Airway Anomalies and Stenosis in Patients with Heterotaxy Syndrome
}

\author{
Mei-Hwan $\mathrm{Wu}^{1}$, Ching-Chia Wang ${ }^{1}$, En-Ting $\mathrm{Wu}^{1}$, Frank $\mathrm{Lu}^{1}$, and Shyh-Jye Chen ${ }^{1}$ \\ ${ }^{1}$ National Taiwan University Hospital
}

December 10, 2021

\begin{abstract}
In heterotaxy syndrome, bronchopulmonary situs usually reflects atrial situs, resulting in either right (RAI) or left atrial isomerism (LAI). This study determines airway anomalies and its implications in patients with heterotaxy. This retrospective study included 223 patients with heterotaxy syndrome who received an integrated cardiac computed tomography evaluation. Patient database from 1995 to 2020 was reviewed. The patients were examined by a congenital heart disease team comprising pediatric cardiologists, radiologists, pulmonologists, and cardiovascular surgeons. Among the 223 patients, 189 (84.8\%, $\mathrm{M} / \mathrm{F}=1.66)$ had RAI and 29 had LAI (13.0\%, M/F=0.71). Five patients had indeterminate isomerism $(2.2 \%, \mathrm{M} / \mathrm{F}=1.5) . \mathrm{Dis}-$ cordant bronchopulmonary and atrial situs occurred in $4 \%$ patients, while discordant bronchopulmonary, atrial, and splenic situs occurred in $23.2 \%$ patients. Lower airway stenosis was observed in 61 patients (27.4\%), including $27.5 \%, 20.7 \%$, and $60 \%$ RAI, LAI, and indeterminate isomerism patients, respectively $(\mathrm{p}=0.189)$. One patient had an intrinsic long segment lower tracheal stenosis and received slide tracheoplasty. Initial cardiac operation was performed in 213 patients. Higher surgical mortality occurred in patients with RAI ( $19.5 \%$ vs. none for LAI and indeterminate isomerism, $\mathrm{p}=0.038)$. In patients with RAI, lower airway anomaly/stenosis increased the duration of ventilator usage $(\mathrm{p}=0.030)$ but did not affect surgical mortality. Total anomalous pulmonary venous return to systemic veins and pulmonary venous stenosis were major surgical risk factors. Bronchopulmonary isomerism shares a similar isomeric pattern to cardiac atrial appendage. Lower airway anomalies/stenosis was common in patients with heterotaxy, resulting in prolonged ventilator therapy in patients with RAI.
\end{abstract}

\section{Introduction}

In humans, the thoracic and abdominal viscera are normally asymmetric and lateralized. Heterotaxy syndrome is a rare form of congenital anomaly caused by laterality disorder during embryogenesis. The prevalence of isomerism was 1.36/10,000 and 0.803/10,000 live births, reported by the European Surveillance of Congenital Anomalies and National Birth Defects Prevention Study conducted in the United States, respectively ${ }^{1,2}$. Heterotaxy syndromes are usually associated with splenic abnormalities and are often referred to as right (RAI) and left atrial isomerism (LAI) or asplenia and polysplenia syndrome, respectively. Right atrial isomerism, or asplenia, is characterized by an absent spleen and duplication of the right-sided structures, including bilateral trilobed lungs and eparterial bronchi. LAI, or polysplenia, is characterized by polysplenia and duplication of the left-sided structures, including bilateral bilobed lungs and hyparterial bronchi ${ }^{3}$.

Complex congenital heart disease (CHD) is often observed in patients with heterotaxy syndrome, particularly in patients with $\mathrm{RAI}^{4}$. Discordant thoracic and visceral situs has also been described. An association of airway anomalies in children with CHD has been reported, mostly in patients with tetralogy of Fallot; the most common was cyanotic CHD. In patients with an extreme form of tetralogy of Fallot, the incidence of airway/lung abnormalities was $31 \%$ (detected by computed tomography (CT) imaging), although the overall incidence of difficult airways was around $5 \%^{5}$. Airway anomalies associated with heterotaxy syndrome may increase perioperative risk and long-term morbidities. 
In most Western countries, patients with LAI account for more than half of patients with heterotaxy syndrome $^{6-9}$. In contrast, more heterotaxy syndrome patients have RAI in oriental reports ${ }^{10-13}$. However, the pulmonary variations and airway anomalies in patients with heterotaxy remain unknown. Most patients with heterotaxy syndrome need to be palliated by multiple staged interventions to achieve a single ventricle due to the associated complex CHD physiology. We hypothesized that the cardiac atrium and bronchopulmonary situs isomerism subtypes were similar but were less similar to the splenic situs. Airway anomalies may be common in patients with bronchopulmonary laterality disorder and might affect surgical outcomes, particularly the initial cardiac operation. Therefore, we investigated the incidence and the clinical implications of lower airway anomalies/stenosis in patients with heterotaxy syndrome, based on a large cohort with extended observation.

\section{Materials and Methods}

Data collection was conducted in accordance with regulations, and this study was approved by the institutional review board of our institution National Taiwan University Hospital (Approval Number: 202109080RINC).

\section{Patient Cohort}

Patients with heterotaxy syndrome who were evaluated with integrated cardiac CT (program started from June 1995) were identified from the patient database (1995-2020) of our institution. Our institution is a tertiary care center with a CHD program in place for more than 50 years. Data collection included demographics, sex, cardiac diagnoses from echocardiography, cardiac catheterization, CT, and cardiac surgeries. Based on the surgical findings and various imaging information, the subtype of heterotaxy syndrome for each patient was further classified as 1) RAI, 2) LAI, or 3) indeterminate isomerism as observed in previous studies by us and other authors ${ }^{8,13}$.

Bronchopulmonary situs and the presence of lower airway anomalies/stenosis were determined using CT imaging. The lower airway anomalies/stenosis included trachea/bronchial stenosis or trachea/bronchus malacia, which were determined with electron beam $\mathrm{CT}^{14}$ or bronchoscopy evaluation. Direct laryngoscopy and/or bronchoscopy were performed when indicated. Patient medical records concerning respiratory care during the initial palliation cardiac surgery were reviewed, including ventilator usage, intensive care unit (ICU) stays, and hospital stays.

\section{Statistics}

The Statistical Package for Social Sciences (SPSS, version 15.0, SPSS Inc., Chicago, IL, USA) was used for analysis. Statistical significance was assessed with independent Student's t-test and ANOVA where appropriate. Descriptive statistics were applied and nominal variables are presented as mean with range. All $\mathrm{p}$ values were two-sided, and a $\mathrm{p}$ value of $<0.05$ indicates statistical significance.

\section{Results}

\section{Patient Characteristics}

We enrolled $223(\mathrm{M} / \mathrm{F}=1.48)$ patients, including 189 patients with $\mathrm{RAI}(84.8 \%, \mathrm{M} / \mathrm{F}=1.66), 29$ patients with LAI $(13.0 \%, \mathrm{M} / \mathrm{F}=0.71)$, and 5 patients with indeterminate isomerism $(2.2 \%, \mathrm{M} / \mathrm{F}=1.5)$.

\section{Bronchopulmonary and Splenic Situs}

The bronchopulmonary and splenic conditions are summarized inTable $\mathbf{1}$. Bronchopulmonary situs was different from the atrial isomerism in four patients with RAI and five patients with indeterminate isomerism. Discordant bronchopulmonary and cardiac atrial situs occurred in $4 \%$ of patients. Asplenia occurred in $81.8 \%$, solitus in $6.9 \%$, inversus in $6.3 \%$, and other splenic anomalies (lobulated spleen) in $5.0 \%$ of patients with RAI. Visceral splenic conditions in patients with LAI included polysplenia (30.7\%), other spleen anomalies (lobulated spleen) (46.2\%), inversus (15.4\%), and solitus (7.7\%). The splenic conditions in indeterminate isomerism included inversus (40\%), asplenia (20\%), and solitus (40\%). Discordant atrial, bronchopulmonary, 
and splenic situs were noted in $23.2 \%$ of patients (44 out of 190 patients with abdominal CT imaging during integrated CHD imaging).

\section{Associated Cardiac Morphology}

The associated cardiac structural abnormalities are summarized inTable $\mathbf{2}$. Total anomalous pulmonary venous return (TAPVR), pulmonary venous stenosis, common atrium, common atrioventricular (AV) valve, double outlet right or indeterminate ventricle, and pulmonary stenosis/atresia were present in over $90 \%$ of patients with RAI. Inferior vena cava interruption was present in all except two patients with LAI. Common atrium, common AV valve, double outlet right ventricle, and pulmonary stenosis/atresia were also common. The morphological characteristics of indeterminate isomerism exhibited a mixed pattern of RAI and LAI.

\section{Associated Lower Airway Anomalies/Stenosis}

Lower airway anomalies/stenosis were found in 61 patients $(27.4 \%)$ (Fig. 1 ), and the incidence was highest in indeterminate isomerism (3 patients, $60 \%$ ), followed by RAI (52 patients, 27.5\%) and LAI (6 patients, $20.7 \%$ ) Table 3 . One patient with indeterminate isomerism had an intrinsic long segment lower tracheal stenosis and underwent slide tracheoplasty.

\section{Risk Analysis for the Initial Palliative Cardiac Operation}

Initial palliative cardiac surgery was performed in 213 patients, and surgical mortality was $16.9 \%$. The surgical mortality was significantly higher in RAI (19.5\%) patients; no surgical deaths occurred in LAI and indeterminate isomerism patients $(\mathrm{p}=0.038)$ Table $\mathbf{3}$. The mean length of hospital stays was $43.3 \pm 65.6$ days and the duration of ventilator usage was $14.9 \pm 28.6$ days $(\mathrm{n}=74)$. Subsequent analyses were made in the RAI subgroup.

In patients with RAI, the presence of TAPVR to systemic veins $(\mathrm{p}<0.001)$ and pulmonary venous stenosis $(\mathrm{p}<0.001)$ were associated with higher surgical mortality. The respiratory and ICU care are summarized in Table 4 . The duration of ventilator usage was significantly higher in patients with lower airway anomalies/stenosis $(\mathrm{p}=0.030)$. Although the presence of TAPVR to systemic veins and pulmonary venous stenosis were important surgical risks, neither significantly increased the duration of ventilator usage.

\section{Discussion}

The clinical implications of lower airway anomalies/stenosis in heterotaxy syndrome, a rare form of congenital laterality defect, are unclear. A study of our large patient cohort revealed several novel findings. The bronchial isomerism subtype was similar to the atrial isomerism but varied more widely in splenic situs. Congenital lower airway anomalies/stenosis are common in heterotaxy syndrome (27.4\%) and might increase the duration of ventilator care during the initial palliative cardiac surgery. Nevertheless, cardiac anomalies, such as TAPVR to systemic veins and pulmonary venous stenosis, affected surgical mortality.

The definition of heterotaxy syndrome subtypes is usually based on the isomeric pattern of the atrial appendages, which is determined by surgical findings and advanced imaging, such as cardiac CT programs ${ }^{3,15}$. The bronchopulmonary situs pattern can also be defined using cardiac CT imaging. In addition, the splenic situs can be delineated by imaging extending to the upper abdomen. Clinical recognition of heterotaxy subtypes is important because they affect outcomes ${ }^{1}$. In general, patients with RAI present with common atrium, common AV valve, double outlet right ventricle, totally anomalous pulmonary venous connection, and pulmonary stenosis/atresia ${ }^{13}$. The goal of treatment for patients with RAI is to eventually achieve a single ventricle circulation. In contrast, LAI with left bronchial isomerism is rare; congenital cardiac malformations are less complicated in LAI, but LAI is usually associated with interruption of the inferior vena cava. Tachyarrhythmias are common in RAI, while bradycardia is more common in patients with LAI $^{13}$. While asplenia occurs in patients with RAI, multiple spleens are often present in patients with LAI.

Using CT or MRI imaging, Yim et al. described bronchopulmonary isomerism that was discordant with the atrial isomerism in 6 out of 114 patients (5.3\%); classic right or left isomerism of the atrial appendages, 
bronchopulmonary branching, and splenic arrangement was present in $78.5 \%$ of patients ${ }^{16}$. In our cohort, discordant atrial and bronchopulmonary isomerism was noted in $4.0 \%$ of heterotaxy syndrome patients $(9 / 223$, four patients with RAI and five indeterminate isomerism patients). Discordant atrial, bronchopulmonary, and splenic situs were noted in $23.2 \%$ of patients. Thus, laterality disorders share similar patterns for atrial and bronchopulmonary situs, but splenic situs may vary more.

In our study, 61 patients $(27.4 \%)$ had mild to moderate trachea or bronchial stenosis. Although the incidence of lower airway anomalies/stenosis is high in patients with heterotaxy syndrome, the evaluation of airway anomalies/stenosis was seldom mentioned in the literature. Our initial results are based on the integrated cardiac CT program to delineate intracardiac and extracardiac structures in heterotaxy syndrome ${ }^{15}$. Chen et al. measured airway anomalies in CHD patients and the associated tracheal and bronchial stenosis were diagnosed $^{14,17}$. Maeda et al. found that syndromic tetralogy of Fallot is usually associated with a 22q11.2 deletion, especially TOF-PA-MAPCA. Airway malacia is often observed in patients with TOF-PA-MAPCA ${ }^{18}$. Our patients with RAI had the worst surgical mortality from the initial cardiac operation, and ventilator usage was significantly longer in patients with RAI with airway stenosis $(p=0.030)$. The presence of lower airway anomalies/stenosis may lead to difficult extubations from the mechanical ventilator even after a successful cardiovascular operation. Nevertheless, the presence of lower airway anomalies/stenosis did not increase surgical mortality. Although the presence of cardiac anomalies, including systemic TAPVR and pulmonary venous stenosis, was a major risk factor for mortality, cardiac anomalies did not prolong ventilator usage. Preoperative integrated CHD imaging, including the pulmonary venous return and the airway, is mandatory for the surgical plan and postoperative intensive care strategy.

Our study is robust but still has limitations. This was a retrospective study using previously documented cardiac CT, 3D reconstruction, echocardiography, and bronchoscopy reports/images. In this large series, all patients had CT, bronchoscopy, or 3D reconstruction. However, to prevent increased radiation loading in children by dynamic multiple phase CT scanning, the diagnosis of airway malacia was limited to a single-phase CT evaluation. A major strength of our work is the large heterotaxy cohort with complete cardiopulmonary evaluation from an integrated CHD CT program since 1995. Therefore, we could clarify the profile of lower airway anomaly/stenosis in heterotaxy.

\section{Conclusions}

The pattern of bronchopulmonary isomerism is often similar to the isomeric pattern of the cardiac atrial appendage, but less similar to the splenic situs. Lower airway anomalies/stenosis is common in patients with heterotaxy and prolongs ventilator therapy in patients with RAI.

\section{References}

1. Loomba RS. Prevalence of isomerism from a European registry: live births, fetal deaths, and terminations of pregnancy. Congenit Anom (Kyoto) 2016;56:256-257. PMID: 27100043. Epub 2016/04/22.

2. Lin AE, Krikov S, Riehle-Colarusso T, Frías JL, Belmont J, Anderka M, Geva T, Getz KD, Botto LD, National Birth Defects Prevention Study. Laterality defects in the national birth defects prevention study (1998-2007): birth prevalence and descriptive epidemiology. Am J Med Genet A 2014;164a:2581-2591. PMID: 25099286. Epub 2014/08/08. eng.

3. Jacobs JP, Anderson RH, Weinberg PM, Walters HL, Tchervenkov CI, Del Duca D, Franklin RC, Aiello VD, Béland MJ, Colan SD, et al. The nomenclature, definition and classification of cardiac structures in the setting of heterotaxy. Cardiol Young 2007;17:1-28. PMID: 18039396. Epub 2008/02/22.

4. Wu MH, Wang JK, Lin JL, Lai LP, Lue HC, Young ML, Hsieh FJ. Supraventricular tachycardia in patients with right atrial isomerism. J Am Coll Cardiol 1998;32:773-779. PMID: 9741526. Epub 1998/09/19.

5. Wise-Faberowski L, Irvin M, Sidell DR, Rajashekara S, Asija R, Chan FP, Hanley FL, McElhinney DB. Assessment of airway abnormalities in patients with tetralogy of Fallot, pulmonary atresia, and major aortopulmonary collaterals. Cardiol Young 2019;29:610-614. PMID: 31044684. Epub 2019/05/03. 
6. Gottschalk I, Stressig R, Ritgen J, Herberg U, Breuer J, Vorndamme A, Strizek B, Willruth A, Geipel A, Gembruch U, et al. Extracardiac anomalies in prenatally diagnosed heterotaxy syndrome. Ultrasound Obstet Gynecol 2016;47:443-449. PMID: 25847110. Epub 2015/04/08.

7. Lim JS, McCrindle BW, Smallhorn JF, Golding F, Caldarone CA, Taketazu M, Jaeggi ET. Clinical features, management, and outcome of children with fetal and postnatal diagnoses of isomerism syndromes. Circulation 2005;112:2454-2461. PMID: 16216960. Epub 2005/10/12.

8. Niu MC, Dickerson HA, Moore JA, de la Uz C, Valdés SO, Kim JJ, Bard DE, Morris SA, Miyake CY. Heterotaxy syndrome and associated arrhythmias in pediatric patients. Heart Rhythm 2018;15:548-554. PMID: 29154821. Epub 2017/11/21.

9. Bhaskar J, Galati JC, Brooks P, Oppido G, Konstantinov IE, Brizard CP, d'Udekem Y. Survival into adulthood of patients with atrial isomerism undergoing cardiac surgery. J Thorac Cardiovasc Surg 2015;149:15091513. PMID: 25752370. Epub 2015/03/11.

10. Lin JH, Chang CI, Wang JK, Wu MH, Shyu MK, Lee CN, Lue HC, Hsieh FC. Intrauterine diagnosis of heterotaxy syndrome. Am Heart J 2002;143:1002-1008. PMID: 12075255. Epub 2002/06/21.

11. Ozawa Y, Asakai H, Shiraga K, Shindo T, Hirata Y, Hirata Y, Inuzuka R. Cardiac rhythm disturbances in heterotaxy syndrome. Pediatr Cardiol. 2019;40:909-913. PMID: 30877320. Epub 2019/03/17.

12. Lee SH, Kwon BS, Kim GB, Bae EJ, Noh CI, Lim HG, Kim WH, Lee JR, Kim YJ. Clinical characteristics and independent factors related to long-term outcomes in patients with left isomerism. Korean Circ J 2017;47:501-508. PMID: 28765742. Epub 2017/08/03.

13. Wu MH, Wang JK, Chiu SN, Tseng WC, Lu CW, Lin HC, Lin MT, Chen CA. Twin atrioventricular nodes, arrhythmias, and survival in pediatric and adult patients with heterotaxy syndrome. Heart Rhythm 2021;18:605-612. PMID: 33321198. Epub 2020/12/16.

14. Chen SJ, Shih TT, Liu KL, Chiu IS, Wu MH, Chen HY, Lee WJ. Measurement of tracheal size in children with congenital heart disease by computed tomography. Ann Thorac Surg 2004;77:1216-1221. PMID: 15063238. Epub 2004/04/06.

15. Chen SJ, Li YW, Wang JK, Wu MH, Chiu IS, Chang CI, Hsieh SC, Su CT, Hsu JC, Lue HC. Usefulness of electron beam computed tomography in children with heterotaxy syndrome. Am J Cardiol 1998;81:188-194. PMID: 9591903. Epub 1998/05/20.

16. Yim D, Nagata H, Lam CZ, Grosse-Wortmann L, Seed M, Jaeggi E, Yoo SJ. Disharmonious patterns of heterotaxy and isomerism: how often are the classic patterns breached? Circ Cardiovasc Imaging 2018;11:e006917. PMID: 29444810. Epub 2018/02/16.

17. Chen SJ, Lee WJ, Wang JK, Wu MH, Chang CI, Liu KL, Chiu IS, Chen HY, Su CT, Li YW. Usefulness of three-dimensional electron beam computed tomography for evaluating tracheobronchial anomalies in children with congenital heart disease. Am J Cardiol 2003;92:483-486. PMID: 12914888. Epub 2003/08/14.

18. Maeda J, Yamagishi H, Matsuoka R, Ishihara J, Tokumura M, Fukushima H, Ueda H, Takahashi E, Yoshiba S, Kojima Y. Frequent association of 22q11.2 deletion with tetralogy of Fallot. Am J Med Genet 2000;92:269-272. PMID: 10842294. Epub 2000/06/08. 
A

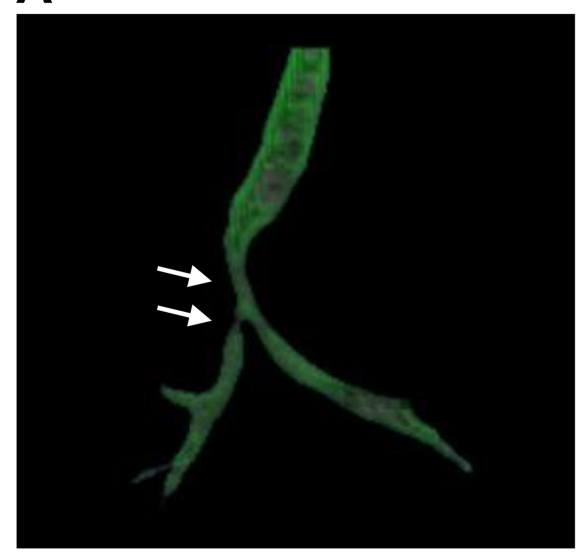

C

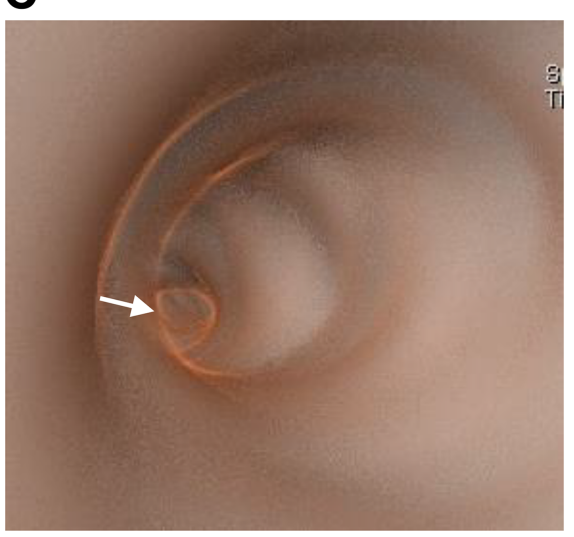

B

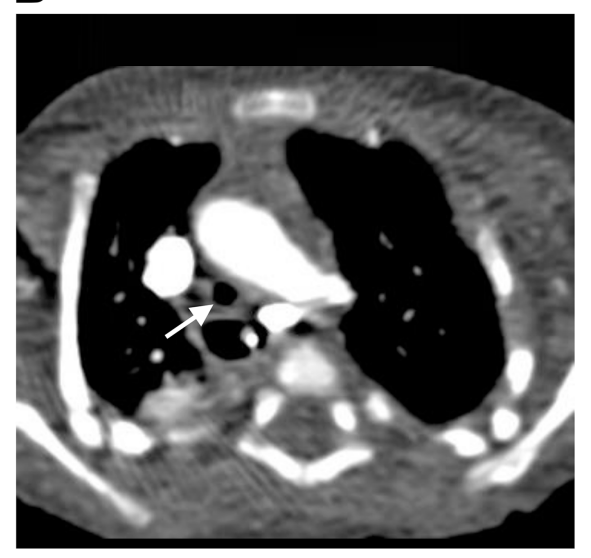

D

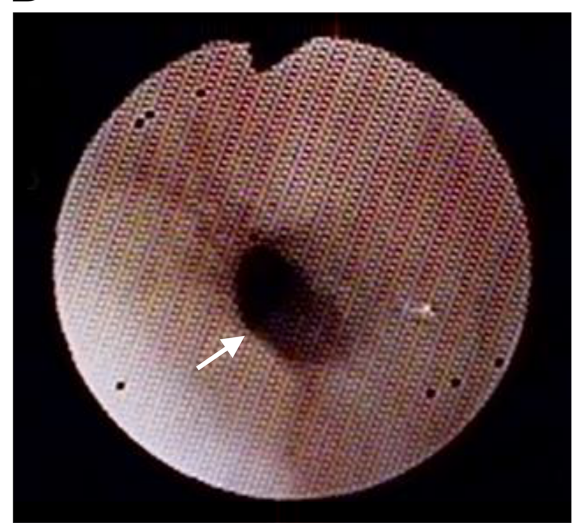

\section{Hosted file}

Table1_ERIWDT-1_EGP_AE-1_MI-2.docx available at https://authorea.com/users/450620/ articles/548921-clinical-implications-of-airway-anomalies-and-stenosis-in-patientswith-heterotaxy-syndrome

\section{Hosted file}

Table2_ERIWDT-1_EGP_AE-1_MI-2.docx available at https://authorea.com/users/450620/ articles/548921-clinical-implications-of-airway-anomalies-and-stenosis-in-patientswith-heterotaxy-syndrome

\section{Hosted file}

Table3_ERIWDT-1_EGP_AE-1_MI-2.docx available at https://authorea.com/users/450620/ articles/548921-clinical-implications-of-airway-anomalies-and-stenosis-in-patientswith-heterotaxy-syndrome

\section{Hosted file}

Table4_ERIWDT-1_EGP_AE-1_MI-2.docx available at https://authorea.com/users/450620/ articles/548921-clinical-implications-of-airway-anomalies-and-stenosis-in-patientswith-heterotaxy-syndrome 